${ }^{10}$ Lee KY, Beilin LJ, Vandongen R. Severe hypertension after ingestion of an appetite suppressant (phenylpropanolamine) with indomethacin Lancet 1979 ; i:1110-1.

${ }^{11}$ McLaren EH. Severe hypertension produced by interaction of phenylpropanolamine with methyldopa and oxprenolol. Br Med f 1976;ii: 283-4.

\section{NHS reorganisation: some hazards for doctors}

On 1 April 1982193 district health authorities will be taking over the running of the NHS in England from 90 area health authorities. Scotland, ${ }^{1}$ Wales, ${ }^{2}$ and Northern Ireland ${ }^{3}$ each has its own NHS reorganisation plans, which do not include the formation of districts, and separate timetables. For England, the Secretary of State for Social Services has, after consultation, decided on the district boundaries for the reorganised Health Service and he is now appointing chairmen. The appointment of staff has been delayed because the National Whitley Council's Reorganisation Committee took longer than expected to agree on terms for the staff affected by reorganisation. ${ }^{4}$ But appointments will soon be taking place, and the BMA, as well as warning its divisions to take an active part in the reorganisation, ${ }^{5}$ has also urged doctors to ensure that "it really is patients first in the new NHS." In particular, consultants in the new district management teams have been asked by $\mathrm{Mr} \mathrm{D}$ E Bolt, chairman of the Central Committee for Hospital Medical Services, to look "very critically at proposals for purely administrative posts at district level." One of the Government's aims in the reorganisation is to save money$£ 30 \mathrm{~m}$ is the target-and to use these administrative savings to improve patient care. Administrators may be sceptical of any oversimplification of the problems of slimming such a complex institution as the NHS, ${ }^{6}$ but those NHS staff dealing with patients' clinical needs will be disappointed if the changes turn out to be a game of administrative musical chairs and the savings illusory.

Many doctors will not be personally affected by reorganisation, but for some doctors in community medicine this will be the second time in a decade that their professional lives will have been disrupted. ${ }^{7}$ Given the recruitment difficulties in community medicine, it is unlikely that there will be unemployment in this craft. Even so, the next few months will be a worrying time for these doctors, and to acquaint the new DHA chairmen with the tasks of community physicians the Central Committee for Community Medicine has just sent them an explanatory booklet, ${ }^{8}$ which among other things declares that "no district will require less than two community physicians (the district medical officer and one other) to provide the essential services." The CCCM's next sentence, that "this should be regarded as a minimum" (the committee's italics), would seem to be an unremarkable statement of the obvious were it not for the genuine concern among community physicians that some DHAs might confine their appointments to the one district medical officer defined among the seven "prescribed" management posts in the reorganisation circular. ${ }^{9}$ All other appointments will be at the discretion of the authorities, and community medicine doctors will be looking for support from their colleagues in the profession to ensure that this branch of medicine is appropriately staffed in the reorganised service.

Consultants, for their part, will welcome their colleagues' support in another unresolved issue in reorganisation: the siting of the consultants' contracts. In Patients First ${ }^{10}$ the DHSS proposed that contracts should be held by DHAs: the BMA strongly opposed this, arguing that they should be held at region, which is where all but teaching hospital consultants' contracts are held at present. No final decision has been made, and presumably the Government hopes that by deferring one until the DHAs are set up the switch could be quietly introduced by individual health authorities, who will understandably see a district-held contract as being administratively tidy and a boost to their power. But consultants will not meekly give way, because they regard this issue as one that affects standards of care.

The arguments for retaining contracts at region are powerful. One of the NHS's successes has been the countrywide provision of a good standard of hospital care. This has largely been a result of regional planning, which includes control over the appointment of consultants. Districts might well adopt a parochial or even a political stance, both in deciding the range of local consultant services and in the consultant appointments themselves. This could hinder the promised expansion of the consultant grade, prove needlessly contentious and uneconomic, and create unacceptable variations in standards of hospital care. A substantial proportion of consultants will have duties extending beyond a single district, so the proposed change would mean either introducing complicated administrative arrangements for sharing contracts between DHAs-several in the case of regional specialties-or requiring individual consultants to hold several small-session contracts. Finally, senior staff in RHAs have developed the knowledge and experience to handle two sensitive aspects of consultant employment-discipline and the sick doctor-and in general they have won the respect and confidence of the profession. District staff would have to acquire this experience, and because they would be responsible for many fewer consultants might not achieve the level of skill now available at regional level. This would be detrimental to the NHS at a time when patients show an increasing tendency to complain about their treatment.

On 28 July the Secretary of State for Social Services told Parliament that he had received over 800 representations on the question of consultant contracts being held at region, mostly from individuals or groups of consultants. Given the reluctance of working doctors to participate personally in medicopolitics, this represents a formidable strength of feeling among consultants. The BMA's Annual Representative Meeting at Brighton also showed the strength of the profession's feelings by voting overwhelmingly in favour of contracts being held by RHAs. The new Secretary of State, $\mathrm{Mr}$ Norman Fowler, should waste no time in endorsing that policy decision by the profession.

${ }^{1}$ Scottish Home and Health Department. Structure and management of the NHS in Scotland. 1981(Gen)14. Edinburgh: SHHD, 1981.

2 Anonymous. $\mathrm{Br} \mathrm{Med} \mathcal{F} 1981 ; \mathbf{2 8 3}: 86$.

3 Anonymous, $\mathrm{Br} \mathrm{Med} \mathcal{F} 1981 ; \mathbf{2 8 3}: 86$.

4 Department of Health and Social Security. NHS reorganisation: implementation of General Whitley agreements. London: DHSS, 1981.

${ }^{5}$ British Medical Association. The BMA division in the new Health Service. London: BMA, 1981.

${ }^{6}$ Anonymous. Hippocratic humbug. Health and Social Service fournal 1981 ; 4 September:1065.

${ }^{7}$ Miles DPB. Community physicians and NHS reorganisation in England. Br Med f $1981 ; 283: 743-4$.

${ }^{8}$ Central Committee for Community Medicine. Community medicine at district in the re-organised NHS 1981-1982. London: British Medical Association, 1981.

${ }^{9}$ Department of Health and Social Security. Health Service development: structure and management. HC(80)8. London: DHSS, 1980.

10 Department of Health and Social Security. Patients first. London: HMSO, 1979. 